\title{
THE PSYCHOLOGICAL BASIS BEHIND NEW MEDIAAS AN IMPETUS BEHIND THE REDUCTION IN PHYSICAL ACTIVITY
}

\author{
Miloš Milošević1*, \\ Nina Pantelić, \\ Tamara Ratković \\ ${ }^{1}$ Faculty of Physical Education and Sports \\ Management, \\ Singidunum University, \\ Belgrade, Serbia \\ ${ }^{2}$ Faculty of Business in Belgrade, \\ Singidunum University, \\ Belgrade, Serbia
}

\begin{abstract}
:
The aim of this paper is to attempt to respond to the issue of the relationship between the reduction in movement and the consumption of new media, as well as the psychological grounds behind such behavior. Through the theoretical analysis of relevant literature, the intention was to primarily extend the conceptual understanding of this important topic. First of all, the nature of digital media and the novelty it brings in relation to analogue media is analyzed. The psychological aspects of new media practices were also analyzed similarly. It was concluded that new media do not contribute anything new in the qualitative sense when it comes to their psychological roles, but that its uniqueness lies in the quantity and intensity of the functions which had previously been carried out by other media. Furthermore, it is incorrect to attribute a reduction in movement of the consumer of new media to the nature of the media themselves. Instead, the solution should be found in the nature of the psychological apparatus and functioning of the consumer. Finally, the need for interdisciplinary study of this important topic was pointed out.
\end{abstract}

Keywords:

Movement, Physical Activity, New media, Digitalization, Psychology.

\section{INTRODUCTION}

The time period from the end of the twentieth and especially the beginning of the twenty-first century stand out when compared with all other previous historical periods primarily due to the radical social changes that took place under the influence of the accelerated development of digital technologies[1]. This is why today's manner of living is unique because, among other things, it brought about the great influence of telecommunications technologies and new media, which have transformed leisure time for children and youth [1], that is, an enormous amount of time spent socializing and entertainment by means of computers, mobile phones, social networks, the Internet, and similar activities which are physically static and often insufficiently challenge the mind, in addition to being asocial [2]. All of this takes place to the detriment of free time spent doing physical activities and physical exercise [3].
Correspondence:

Miloš Milošević

e-mail:

mmilosevic@singidunum.ac.rs 
Physical inactivity is one of the greatest health risk factors [4]. A second significant factor is an excessive and unhealthy diet $[5,6]$. Inactivity in combination with an excessive and unhealthy diet are among the most basic bad habits characteristic to the to aforementioned present-day unhealthy lifestyle, is the most important prerequisite for the origins of obesity, the disruption of postural status and numerous diseases related to the functioning of all tissue and organic systems $[4,5,6,7]$. Technological and societal progress, along with an increase in quality of life, paradoxically, turn the thus-far efficient adaptation mechanisms against the health and well-being of both the individual and society.

Naturally, apart from directly threatening physical health as a consequence of the aforementioned social changes, additional consequences can also be witnessed on the mental health of children and youth. The number of children diagnosed with ADHD (attention deficit hyperactive disorder) has been rising rapidly over the years in the United States of America, where it affects over $11 \%$ of preschool and elementary school-aged kids [8]. The number of children with similar symptoms who are not registered in the healthcare system or who live with milder symptoms of the disease is significantly higher. Hyperactivity and the inability to focus one's attention negatively impact learning and success in schools [9], as well as functioning in social situations, and can lead to increased aggression [10]. Regardless of whether the issue is a diagnosed syndrome or a milder case of attention disorder, more work and stimulation must be invested in children in order to avoid poor development. Although studies indicate that physical activity has a positive effect on children with ADHD [11,12] and work on the development of attention and other cognitive capabilities [13], not enough detailed research has been carried out on the connection between concrete cognitive and motor skills [14]. As such, even though physical activity is proclaimed by institutions, the media, and education workers, as an efficient mode of changing negative behavioral manifestations, particularly in a scholastic environment, it is easy to realize that there is a lack of specification of such recommendations, namely, what type, how much, and other questions related to physical activities, ought to be practiced. On the other hand, although the cause behind these changes is still uncertain, it could be sought within the trend of a reduction in physical activity and an increase in the amount of time children spend in front of televisions, computers, mobile phones, and similar media gadgets [15]. Some experimental studies suggest the same out- come [16]. Since it is unlikely that the trend of increased media presence in everyday life will change anytime soon, it can be concluded that the number of children with problems focusing will continue to increase in the future.

Given the aforementioned reasons, the question is posed as to the psychological motivations behind the production and consumption of media content, bearing in mind how widespread this behavior is, as well as the psychological implications such behavior has on the development of individuals and of society itself. The COVID-19 pandemic has led to an even further reduction in movement, and to an increase in the significance the media has on and influences everyday life. This has updated the need for its further deliberation, as well as for seeking new methods for combatting said problems.

The aim of this paper is to attempt to respond to the question of the relationship between movement and the consumption of new media, as well as the psychological grounds behind such behvariour, through the theoretical analysis of relevant literature. Given that the aspects of social change brought about by new media have already been thoroughly described in earlier studies, emphasis in this work shall be placed on the individual psychological aspects and their implications..

\section{THE DIGITAL NATURE OF NEW MEDIAAND MOVEMENT IN THE PHILOSOPHY OF MEDIA}

When considering the process of digitalization, which is an integral process for the subject matter of this paper, the question of the nature of knowledge and existence (as a basic ontological question) can additionally be re-formulated as a question of the digital and analogue in relation to the process of movement and cognition - the eternal question of the relation between spirit and body. Reflecting on the nature of the virtual, which in and of itself is inaccessible to the senses yet originates within an act of imagination, Brian Massumi describes the concepts of topology and probability. In fact, in addition to topology and probability, Massumi uses the term potential, which is derived from probability, that is, it represents one of the variations of its expression. "When most attentive to the virtual, qualification deforms into the topo-ontological exercise of contingent reason (thought bending back to participate in its own emergence from sensation; imagination, or intuition in Bergson's sense)" [17:136]. The conclusion can be reached that moving one's body through space 
while thinking is an analogue process, while the body in motion paints thoughts, that is, it reflects. On the other hand, digital codification, which lacks the continuity of topology and transformation, is merely a probability. "Nothing is more destructive for the thinking and imaging of the virtual than equating it with the digital" [17:137]. However, although at first glance this sharply demarcates the virtual and the digital, Massumi is aware that the analogue processes may rely on digital coding, and that the process of digitalization is a two-way street, and does not necessarily exclude analogue processing. "The digital is sandwiched between an analogue disappearance into code at the recording and an analogue appearance out of code at the listening end" [17:138]. This refers to the recording and listening of sounds, which is used as a metaphor for the digital recording of analogue signals and the analogue processing of digital signals. Hence, the roles of neither of the two modalities of recording and processing of information, that is, their complementary roles in the origins of the virtual, should be neglected.

Unlike Massumi, who recognizes the connection between the body and cognition because " $[t]$ here is no thought that is not accompanied by a physical sensation of effort or agitation " [17:138], yet hands the advantage to analogue processing (and recording) in the description of the body in motion, Mark Hansen, through the "theorize the correlation of new media and embodiment" [18:11] in the process of digitalization finds a new qualitative leap towards the body as an active participant in the process of constructing the meaning and understanding of reality. ,[R]ather than selecting preexistent images, the body now operates by filtering information directly and, through this process, creating images" $[18: 10]$. This primarily refers to the possibility of generating digital information (images) without the need for physical (external) references. „[T]he "image” has itself become a process and, as such, has become irreducibly bound up with the activity of the body" [18:9]. Still, although digital technologies may be labelled as evidence of the processing nature of images, as well as the creative roles of the body in its construction, it would be wrong to link these functions solely with digital media. When approaching analogue signals, the body makes contact with information, which it filters. Even if information could be be constructed as an existing image, the creative nature of the body in its processing is not much different to that of the digital signal. Perception is, as a cognitive process, equally reliant upon the body in both a digital and analogue environment. The same is true for its constructivist nature.
The newly created change is a change in the stress, the stripping down of, and the awareness of these processes, which are made possible thanks to interaction of the human body with a digital environment. "In sum, the image can no longer be restricted to the level of surface appearance, but must be extended to encompass the entire process by which information is made perceivable through embodied experience" [18:9]. This should particularly be kept in mind when the term post-screen [19] images is postulated and used. Digital technologies have, to some extent, enabled the transcendence of the screen as a technological necessity, but this did not change the nature of the concept of images. Instead, the nature of a lower concept of media images has become closer to the nature of the basic concept. Or, perhaps more radically, it could be claimed that the transcendence of screens did not lead to an ontological change, but rather a clearer observation into the nature of the concept. Regardless of the designation towards the nature of change, the subject discovers that the instance of appearance of the image becomes a relevant subject for researching the theory of media (through which it also bridges the gap with cognitive sciences).

Theory and the philosophy of media are often too critical and neglect the numerous positive consequences of the development of technology. As such, negative consequences are often attributed to the nature of new media. "Rather than being a neutral medium of presenting information, the screen is aggressive. It functions to filter, to screen out, to take over, rendering non-existent whatever is outside its frame" [20:100]. Nevertheless, numerous examples lead to the conclusion that the human subject is capable of habituating irrelevant stimuli even more aggressive and life-threatening than the media screen, including explosions or the sound of guns shooting during prolonged war situations. Understanding the attractive nature of the screen is insufficient without understanding the psychological (particularly the conative and emotional) grounds of the consumption (and production) of media content.

\section{THE PSYCHOLOGICAL INFLUENCE AND ROLE OF NEW MEDIA}

What is new in the psychological sense which new media and new technologies bring about with them? Is it that their widespread use is connected with the radically different psychological functioning of the subject and new media discourse? Or have new technologies "merely" enabled the easier and simpler fulfilment of age-old psychological desires? 
Firstly, it merits observing that the production of online video clips and similar new media content, as well as their sharing on the web as a means of expression and communication, have a psychological basis and function similar to those of traditional media. In addition to expression and communication, informing oneself, creativity, and a reduction in uncertainty could be listed as further themes. This is coupled with the desire to earn money - and fame - which designates them as a practice on the border between the professional and the amateur. As new media content is most often a part of social media, the themes of belonging, gratification, distraction, self-representation and self-promotion can also be observed [21,22]. Self-actualization, learning, entertainment, and spending one's free time are just some more in a long line of important features of the production and consumption of online video clips that traditional and new media share. Finally, the fulfilment of exhibitionist and voyeuristic needs, as well as narcissism [23] are all something they have in common with other media, which deserves to be mentioned as well.

Nonetheless, given that they represent an expression of democratization and the widespread practice of audio-visual production, online video clips and similar new media content represent the continuation of the process of grammatization, that is, the spatialization of the course of time dating back all the way to the Neolithic period [24]. Similar as the appearance of letters allowed for the copying and reproduction of speech, audio-visual production represents the next stage in the reproduction of the course of time, which will allow for a new stage in the psychological individuation of humankind and society [24]. Thus, it can be concluded that the development and creation of one's own identity and its separation from the collective identity typical for a childish character [25], that is, maturing, can at an individual level be achieved (or at least supported) through recording primarily one's self and one's surroundings, but also in the browsing of others' content. The role of new media content is, therefore, greater and more important among the youth and adolescent population, while its significance should drop through the process of maturing.

Finally, new media content must be mentioned as a practice for the archiving of one's own life [22] in an attempt to overcome the fear of death, as well as its therapeutic effect in overcoming bad experiences and emotions [26]. However, roles similar to that of new media content, identity creation, the process of individuation, the archiving of one's own life, overcoming bad emotions and events, can be found in the writing of diaries or in filming, photographing one's self - or surroundings or families, as was common practice in the pre-digital age.

The consumption of new media represents a type of addiction and emotional investment which can be clearly observed once access to new media is enabled [27]. Mobile telecommunications devices in the life of the modern man attain the feature of a transient object, both as its externally clear and noticeable function of relieving stress and uncertainty in the process of individuation and testing reality, as well as in mediating between the inner (subjective) and outer (objective) world [28]. New technologies and new media, far more so than their traditional antecedents, have the capacity to allow their subject the regressive (and autoerotic) illusion of creating reality, which somewhat drain their addictive power. The virtual reality of new media (discussed earlier through the issues of critiquing their ontologies) enable the subject to get closer to the phantasmatic reality of their early childhood, which was created exclusively by instinct, without the intervention of the outside world [29]. In this capacity of the first subject's reality, a deep conative basis can be sought in the need for constructing virtual realities which are fulfilled (or at least attempt to) by the consumption of media content [30]. This aspect, often insufficiently analyzed or completely neglected, is essential to the true understanding of new media practices, their development, and the nature of human beings. Similarities between primary (instinctual) reality and virtual reality can be observed easily in dreams [31], whose nature is still not satisfactorily explained. These media constructed realities become equally of the subject of interest in of study in psychology as in the theory of media and film.

\section{CONCLUSION}

When it comes to workers in sports and physical education, knowledge of the theoretical settings of other social-humanistic disciplines, especially the neglected theories of media and film, is necessary in order to properly confront the aforementioned challenges that technological progress brings.

Based on all of the above, the conclusion is that new media do not contribute anything new in the qualitative sense when it comes to their psychological roles, but that its uniqueness lies in the quantity and intensity of the functions which had previously been carried 
out by other media. However, this novelty, because it is so widespread, must bring about with it changes in the psychological functioning of the individual and, simultaneously, social change as well. Furthermore, it is incorrect to attribute a reduction in movement of the consumer of new media to the nature of the media themselves. Instead, the solution should be found in the nature of the psychological apparatus and functioning of the consumer.

Reliance upon new media for the development of technology is a guarantee of its future influence. The current COVID-10 pandemic implied as much. Still, although technological development cannot be prevented, what is assured is that, nowadays, it could derail the development of humanity. A noticeable reduction in movement as a consequence of the consumption of media content can also be fatal for the subject - at least until the still very unlikely possibility of body transcendence is not achieved. Societal-humanistic sciences have an obligation to indicate these possibilities in order for their influence to go beyond critique and for the message to be one of prevention they must increase their social influence and relevance. This paper is an attempt to move in that direction.

Integrating new technologies into healthy lifestyles appears to be a much more appropriate and realistic solution than fighting technological progress, or outright banning the use of technology.

\section{REFERENCES}

[1] Milošević, M. (2019). Srpski film u doba novih medija (2010-2016). Beograd: Fakultet dramskih umetnosti.

[2] Milošević, M., \& Čolović, M. (2019). RAZVOJNA I PEDAGOŠKA PSIHOLOGIJA, sa primenom u sprtu i fizčkom vaspitanju. Beograd: Univerzitet Singidunum.

[3] Marković, V., Živković, A., \& Milošević, M. (2019). Plivanje u fizičkom vaspitanju dece. 1. Nacionalna naučna i stručna konferencija, Aktuelnosti u teoriji i praksi sporta, fizičkog vaspitanja i rekreacije. Fakultet sporta i fizičkog vaspitanja Univerziteta u Beogradu

[4] World Health Organisation. (2018). World health statistics 2018: monitoring health for the SDGs, sustainable development goals. Luxembourg: World Health Organization.

[5] Popović, J., Grbić, S., Milošević, M., Ilić, R., \& Kilibarda, N. (2019). Food Flavour as Influence Factor for Balanced Diet for Children. Quality of Life, 10(1-2): 55-59.
[6] Stanišić, S. (2019). Ishrana i zdravlje. Beograd:Delfi.

[7] Ilić, R., Popović J., Marković V., Nemec V., \& Milošević, M. (2019). Work-Related Stress Among Primary Healthcare Workers. Vojnosanitetski pregled, OnLine-First (00):20-20. DOI: https://doi. org/10.2298/VSP181228020I

[8] Visser, S.N., Danielson, M.L., Bitsko, R.H., Holbrook, J.R., Kogan, M.D., Ghandour, R.M., Peroru, R., \& Blumberg, S.J. (2014). Trends in the parentreport of health care provider-diagnosed and medicated attention-deficit/hyperactivity disorder: United States, 2003-2011. Journal of the American Academy of Child and Adolescent Psychiatry, 53(1):34-46. e2. doi: 10.1016/j.jaac.2013.09.001.

[9] Barry, T.D.S., Lyman, R.D., \& Klinger, L.G. (2002). Academic Underachievement and Attention-Deficit/Hyperactivity Disorder: the Negative Impact of Symptom Severity on School Performance. Journal of School Psychology, 40(3):259 -283. doi: 10.1016/ S0022-4405(02)00100-0.

[10] Mannuzza, S., Klein, R.G., Abikoff, H., \& Moulton, J.L. (2004). Significance of Childhood Conduct Problems to Later Development of Conduct Disorder Among Children with ADHD: a Prospective Follow-Up Study. Journal of Abnormal Child Psychology, 32(5):565-573.

[11] Hartanto, T.A., Krafft, C.E., Iosif, A.M., \& Schweitzer, J.B. (2016). A Trial-by-Trial Analysis Reveals More Intense Physical Activity is Associated With Better Cognitive Control Performance in Attention-Deficit/Hyperactivity Disorder. Child Neuropsychology, 22(5):618-26. doi: 10.1080/09297049.2015.1044511.

[12] Cornelius, C., Fedewa, L.A., \& Ahn, S. (2017). The Effect of Physical Activity on Children With ADHD: A Quantitative Review of the Literature. Journal of Applied School Psychology. , 33:2, 136170. doi: 10.1080/15377903.2016.1265622.

[13] Lambourne, K., \& Tomporowski, P. (2010). The Effect of Exercise-Induced Arousal on Cognitive Task Performance: a Meta-Regression Analysis. Brain Research, 1341:12-24. doi: 10.1016/j.brainres.2010.03.091.

[14] Gapin, I.J., Labban, D.J., \& Etnier, L.J. (2011). The Effects of Physical Activity on Attention Deficit Hyperactivity Disorder Symptoms: The Evidence. Preventive Medicine, 52:70-74. doi: 10.1016/j. ypmed.2011.01.022.

[15] Eaton, D.K., Kann, L., Kinchen, S., Shanklin, S., Flint, K.H., Hawkins, J., Harris, W.A., Lowry, R., McManus, T., Chyen, D., Whittle, L., Lim, C., \& Wechsler, H. (2012). Youth risk behavior surveillance - United States, 2011. MMWR Surveillance Summaries, 61(4):1-162. 
[16] Swing, L.E., Gentile, A.D., Anderson. A.C., \& Walsh, A.D. (2010) Television and Video Game Exposure and the Development of Attention Problems. Pediatrics, 126(2): 214-221. doi: 10.1542/peds.2009-1508

[17] Massumi, B. (2002). Parables for the Virtual: Movement, Affect, Sensation. Durham: Duke University Press.

[18] Hansen, M. (2004). New Philosophy for New Media. Cambridge: MIT Press.

[19] Bosma, J. (2013). Post-Digital is Post-Screen: Arnheim's Visual Thinking Applied to Art in the Expanded Digital Media Field. A Peer-Reviewed Journal About Post-digital Research: http://www.aprja. net/post-digital-is-post-screen-arnheims-visualthinking-applied-to-art-in-the-expanded-digitalmedia-field/?pdf=1892. Accessed May 1st, 2020.

[20] Manovich, L. (2001). The Language of New Media. Cambridge: MIT Press

[21] Peek, H. (2014). The Selfie in the Digital Age: From Social Media to Sexting. Psychiatric Time,: http:// www.psychiatrictimes.com/cultural-psychiatry/ selfie-digital-age-social-media-sexting. Accessed May 1st, 2020.

[22] Yongjun, S., Jung-Ah, L., Eunice, K., \& Sejung, C. (2016). Why We Post Selfies: Understanding Motivations for Posting Pictures of Oneself. Personality and Individual Differences, 97: 260-265.

[23] McCain, J., Borg, Z., Rothenberg, A., Churillo, K., \& Weiler, P. (2016). Personality and selfies: Narcissism and the Dark Triad. Computers in Human Behavior, 64:126-133.
[24] Stiegler, B. (2009). The Carnival of the New Screen: From Hegemony to Isonomy. in Snikkars, P., \& Vonderau, P (eds). The You Tube Reader. London: Wallflower Press, 40-60.

[25] Jung, C. (1971). Psychological Types (The Collected Works of C. G. Jung, Vol. 6). London: Routledge.

[26] Chang, JH., Huang, CL., \& Lin, YC. (2013). The Psychological Displacement Paradigm in Diary-Writing (PDPD) and its Psychological Benefits. Journal of Happiness Studies, 14 (1):155-167.

[27] Luskin, B. (2017). The Media Psychology Effect. Psychology Today: https://www.psychologytoday. com/blog/the-media-psychology-effect/201609/ explaining-media-psychology-in-2017. Accessed May 1st, 2020.

[28] Winnicott, D. (1953). Transitional Objects and Transitional Phenomena. International Journal of Psycho-Analysis, 34:89-97.

[29] Klein, M. (1930). The Importance of Symbol-Formation in the Development of the Ego. International Journal of Psycho-Analysis, 11:24-39.

[30] Milošević, M. (2019). Digital moving image as the subject of digital film, media and culture studies. NEW HORIZONS Culture, Arts and Media in the Digital Environment (pp.108-109). Fakultet dramskih umetnosti, Beograd.

[31] Milošević, M. (2017). Film i san. Zbornik radova fakulteta dramskih umetnosti, 32:27-42. 